\title{
The effect of paratuberculosis on milk yield-A systematic review and meta-analysis
}

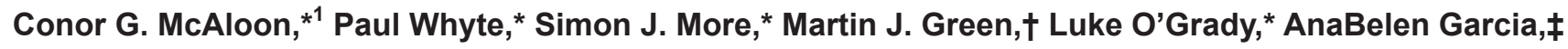 \\ and Michael L. Doherty* \\ *Section of Herd Health and Animal Husbandry, School of Veterinary Medicine, University College Dublin, Belfield, Dublin 4, Ireland \\ †School of Veterinary Medicine and Science, University of Nottingham, Sutton Bonington, LE12 5RD, United Kingdom \\ $\ddagger$ Animal and Grassland Research and Innovation Centre, Teagasc Moorepark, Fermoy, Co. Cork, Ireland
}

\begin{abstract}
Bovine paratuberculosis is a disease characterized by chronic granulomatous enteritis causing protein-losing enteropathy. Adverse effects on animal productivity are key drivers in the attempt to control paratuberculosis at the farm level. Economic models require an accurate estimation of the production effects associated with paratuberculosis. The aim of this study was to conduct a systematic review and meta-analysis to investigate the effect of paratuberculosis on milk production. A total of 20 effect estimates from 15 studies were included in the final meta-analysis. Substantial between-study heterogeneity was observed. Subgroup analysis by case definition and study design was carried out to investigate heterogeneity. The majority of between-study variation was attributed to studies that defined cases on serology. Calculation of a pooled effect estimate was only appropriate for studies that defined cases by organism detection. A reduction in milk yield, corrected for lactation number and herd of origin of $1.87 \mathrm{~kg} / \mathrm{d}$, equivalent to $5.9 \%$ of yield, was associated with fecal culture or PCR positivity in individual cows.
\end{abstract}

Key words: paratuberculosis, Johne's disease, metaanalysis, milk yield

\section{INTRODUCTION}

Bovine paratuberculosis is a disease characterized by chronic granulomatous enteritis, which manifests clinically as a protein-losing enteropathy causing diarrhea, hypoproteinemia, emaciation, and, eventually, death (Sweeney et al., 2012). Adverse effects on animal productivity and losses due to continued spread of in-

Received July 22, 2015.

Accepted October 23, 2015.

${ }^{1}$ Corresponding author: mcaloonconor@gmail.com fection are key drivers in the attempt to control the disease at the farm level. Some research exists to suggest that the etiologic pathogen Mycobacterium avium ssp. paratuberculosis (MAP) may pose a zoonotic risk, and a potential association with Crohn's disease exists in humans (Chiodini et al., 2012). Consequently, many major dairy-producing countries have introduced control programs aimed at reducing spread between and within herds (Geraghty et al., 2014).

Farm-level losses associated with the effect of paratuberculosis on production are often cited as important drivers in the need to control the disease on dairy farms. Several studies have been published on the economic effect of paratuberculosis at the farm level, with estimates generally in the range of $\$ 20$ to $\$ 50$ per cow in infected herds (Ott et al., 1999; Chi et al., 2002; Stott et al., 2005).

Economic models commonly use production loss estimates from a chosen observational study to investigate the effect of infection on milk production. However, a substantial number of these studies available in the literature report varying effect estimates. Whereas many studies have found a significant association between animals testing positive for MAP and reductions in milk production, others have reported a nonsignificant reduction or, in some cases, an increase in production associated with diagnostic test positivity (Garcia and Shalloo, 2015).

Narrative reviews of the effect of paratuberculosis on milk production are widely available in the literature; however, these are subjective in nature and therefore prone to reviewer bias (Blettner et al., 1999). Systematic review and meta-analysis represents a quantitative approach to combining information from multiple research studies. In addition, meta-analysis represents a useful approach to investigating sources of heterogeneity between observational studies. The objective of our study was to conduct a systematic review and meta-analysis of the effect of paratuberculosis diagnos- 
tic test positivity on milk yield to investigate betweenstudy heterogeneity and, where appropriate, calculate a pooled effect estimate of the effect of diagnostic test positivity on milk yield.

\section{MATERIALS AND METHODS}

The study was conducted in compliance with consensus guidelines for the meta-analysis of observational studies in epidemiology (MOOSE; Stroup et al., 2000). In this case the question was, "What is the effect of paratuberculosis infection on milk yield in dairy cattle?" Review questions were often further defined in terms of the population, intervention, comparator, outcome, and study design (EFSA, 2010). In this case, the population of interest was dairy cattle, the intervention was infection as determined by ELISA positivity or detection of the organism (MAP) in feces by culture or PCR; the comparator was diagnostic test negative animals; the outcome of interest was the deviation in milk yield; and the required study design for inclusion in the analysis was cross sectional or longitudinal.

\section{Literature Search}

The primary author (C. McAloon) searched the electronic databases PubMed (http://www.ncbi.nlm.nih. gov/pubmed) and CABDirect (http://www.cabdirect. $\mathrm{org} /$ ) in January 2015 using the search terms "bovine OR cattle OR cows" and "paratuberculosis OR Johne's" and "yield OR production OR effect" and "milk." The search was conducted on all available years, on all types of articles (both peer-reviewed and nonreviewed), and was not limited to abstracts or titles. In addition, the reference lists from these papers were hand searched to identify additional relevant studies. These were subsequently added to the master list $(\mathrm{n}=76)$.

\section{Eligibility Screening: First Phase}

The first phase of the eligibility screening was conducted by the first author based on the information presented in each abstract. The following inclusion criteria were used: (1) studies reported in English, (2) seeking to quantify the level of milk production deviation in test-positive animals, and (3) conducted at the level of the individual animal (rather than the herd). All eligible papers $(\mathrm{n}=44)$ were then retained for phase 2 screening.

\section{Eligibility Screening: Second Phase}

Phase 2 screening was also conducted by the first author. Each full paper was reviewed with particular attention to the materials and methods. Authors were contacted for papers that were unavailable for access, but if the required study detail was not included in the published article we made no attempt to contact the author regarding missing data. Studies were considered eligible at this level if they addressed the following criteria: (1) compared milk yield between diagnostic test-positive and diagnostic test-negative dairy cows; (2) used original data that has been not used in a subsequent study; (3) reported an effect estimate and a corresponding uncertainty term; and (4) attempted to address key confounders in the statistical analysis, including herd or farm and parity.

\section{Data Extraction}

Following the compilation of the final list of studies (n =33), data were extracted according to Supplementary Table S1 (http://dx.doi.org/10.3168/jds.2015-10156). Deviation in milk yield was extracted as kilograms of milk per cow per day. Study outcomes reported as 305-d milk yield were converted to a daily figure by dividing by 305 . Fat and protein yields were extracted as grams per day. In the case of milk constituents being reported as a percentage, absolute yield was calculated by multiplying by the daily milk yield. Outcomes that were reported by lactation were extracted individually. When different case definitions were used in the same publication, each case definition was extracted as a separate study. Data were not read from figures.

To estimate the deviation of milk yield as a percentage of expected production, milk yield of the negative subgroup was extracted as a baseline. When these data were not presented in a study, the overall yield of the entire study population was extracted from the descriptive statistics. When neither of these sources were reported in the study, the intercept of the multivariate model was adjusted to lactation 3 and used. Finally, in the absence of any of the above information reported in the study, the average yields per cow over the time period coinciding with the sampling frame outlined was obtained for the relevant geographical region. These data were sourced from the National Animal Health Monitoring System (J. E. Lombard, Fort Collins, Colorado, personal communication) or the National Agricultural Statistics Service (USDA, 2015).

All error terms were extracted as a standard error (SE). When an SE was not reported, $P$-values were converted to $t$ values that were, in turn, converted to $\mathrm{SE}$ in line with Cochrane Handbook guidelines for data extraction for continuous outcomes (Higgins and Green, 2011). If the SE was reported for a 305-d yield, this was converted to a daily SE by dividing by 305 . When data were reported as being significant at $P=$ 0.05 , a $P$-value of 0.05 was assumed for the study. 


\section{Pooling Subgroups}

Subgroups of case definitions and lactation number were combined when no overall effect was provided. A combined effect estimate was calculated by a weighted mean of the subgroup estimates and a standard error for this combined effect was calculated from the square root of the average variances of the subgroups.

\section{Statistical Analysis}

Studies were further screened before meta-analysis with the intention of including comparable outcomes in the analysis. Studies that quantified milk yield over the lifetime of the animal were not included. Where possible, case definitions that combined diagnostic tests were not included; for example, the case definition "ELISA positivity or fecal culture" was not included. Case studies were also not included in the meta-analysis given the small number of these studies.

Random effects models were constructed to investigate the deviation in milk yield as an absolute value and as a percentage of overall yield. Models were also constructed to investigate the effect on milk fat and protein. In a random effects meta-analysis, the underlying effect of infection on milk production is allowed to vary for each study. The model was constructed using the metan command in STATA (Harris et al., 2008) and the Higgins statistic $\left(\boldsymbol{I}^{2}\right)$ was used to assess betweenstudy heterogeneity (Higgins and Thompson, 2002). This value ranges from 0 to $100 \%$ and represents the percentage of the variation in the point estimate that can be attributed to study heterogeneity rather than chance (Higgins et al., 2003). The following guidelines have been suggested for interpretation of the Higgins statistic: unimportant (0-40\%), moderate (30-60\%), substantial (50-90\%), and considerable (75-100\%; Deeks et al., 2008). When substantial heterogeneity was present, data sets were subgrouped to investigate possible sources of heterogeneity. Publication bias was investigated using funnel plots and tested using Egger's test (Egger et al., 1997). Finally, a sensitivity analysis was conducted by varying some of the decisions made around study selection criteria and repeating the analyses.

\section{RESULTS}

\section{Study Selection: Phase 1}

The initial search in PubMed and CABdirect resulted in 375 and 140 returned articles, respectively. After reading the titles of the returned papers and combining results from both search engines, 60 eligible papers were identified. The reference lists of these papers were hand searched and a further 16 papers were added to the main list. Of the 76 eligible articles during phase 1 screening, 9 papers were excluded as review articles, 4 were excluded as herd-level studies, 10 were excluded as economic studies that used production data from another study, and a further 3 studies were excluded as not having been published in English. Six articles were also excluded, as it appeared they were not relevant to the particular research question (i.e., they did not aim to quantify the level of milk loss).

\section{Study Selection: Phase 2}

During the second phase of eligibility screening, 4 studies were excluded because the data had been published in a subsequent study (Kudahl et al., 2003; Lombard et al., 2005b; Sorge et al., 2007; VanLeeuwen et al., 2002). Fifteen studies were excluded because the required level of detail was not reported regarding the estimate and error term (Whitlock et al., 1985; Wilson et al., 1993; Chaffer et al., 2002; Hoogendam et al., 2009; Sibley et al., 2012), the outcome was not comparable (DeLisle and Milestone, 1989; Nielsen et al., 2009), they did not (or did not appear to) account for herd as a possible confounder (Collins, 1991; Sweeney et al., 1994; Raizman et al., 2007, 2009; Pantoja et al., 2010), parity or age did not appear to be accounted for in the analysis (Rad et al., 2010), or the comparisons were between different lactations within the same animal (Benedictus et al., 1986, 1987). Two studies were unavailable (Dinsmore, 1986; Pavlík et al., 1994).

The final list following phase 2 screening consisted of 33 studies from 20 publications (Table 1). Two were from conference proceedings and 31 were from peer-reviewed journals. Year of publication ranged from 1978 to 2014 and numbers of cases ranged from 8 to 1,382 . Point estimates of production differences associated with paratuberculosis test positivity ranged from -4.87 to $3.15 \mathrm{~kg} /$ cow per day. Overall, 6 studies demonstrated a positive association between test-positivity and milk yield and 22 demonstrated a negative effect. Five studies reported the outcome by lactation number rather than the overall effect (Table 2).

For the meta-analysis, a final table (Table 3) was produced that included observational or cross-sectional studies using ELISA or fecal culture and PCR as the case definition and measured milk yield deviation for the lactation corresponding to the diagnostic test, rather than lifetime production of the animal. Pooled estimates across lactation number or case definitions were included and studies were removed where the case definition was ELISA-positive or fecal culture and PCR, or where the case definition was latent. Simi- 
Table 1. Data extracted from studies investigating the effect of paratuberculosis on milk production

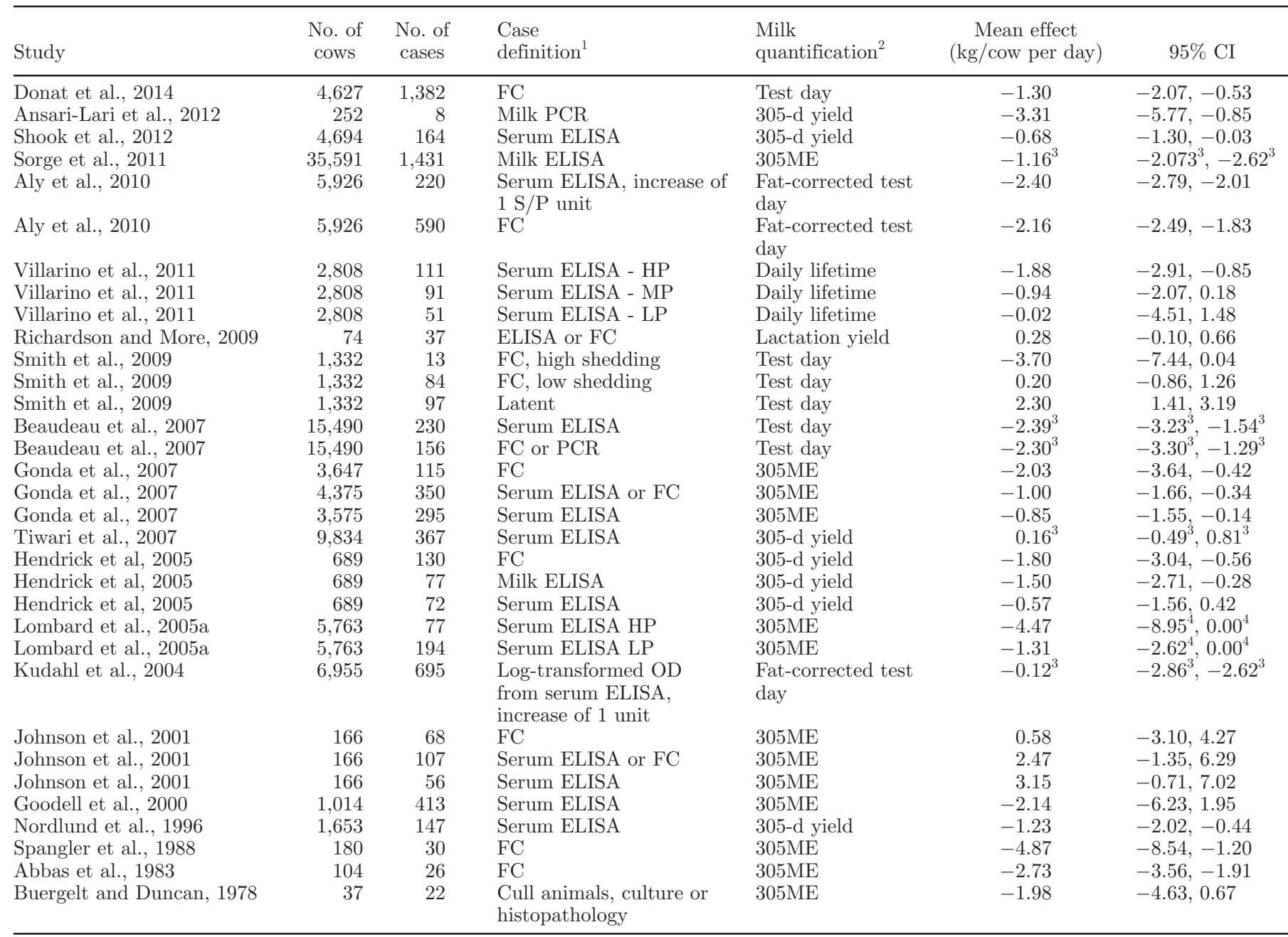

${ }^{1} \mathrm{FC}=$ fecal culture, $\mathrm{S} / \mathrm{P}=$ sample/positive, $\mathrm{LP}=$ low positive, $\mathrm{MP}=$ medium positive, $\mathrm{HP}=$ high positive, $\mathrm{OD}=$ optical density.

${ }^{2} 305 \mathrm{ME}=305$-d mature-equivalent yield.

${ }^{3}$ Weighted mean of outcomes reported by lactation number.

${ }^{4}$ Calculated assuming $P=0.05$.

lar tables were constructed from studies investigating milk fat yield (Supplementary Table S2; http://dx.doi. org/10.3168/jds.2015-10156) and milk protein yield (Supplementary Table S3; http://dx.doi.org/10.3168/ jds.2015-10156).

\section{Meta-Analysis}

Longitudinal and cross-sectional studies that used either milk or serum ELISA or fecal culture or PCR were pooled for analysis (Table 3). Twelve random effects meta-analyses models were constructed to investigate the effect of paratuberculosis on milk production, model outcomes are summarized in Table 4. Analysis of all case definitions and study designs together (Supplementary Figures S1 and S2; http://dx.doi.org/10.3168/ jds.2015-10156) resulted in a point estimate of -1.30 $(95 \% \mathrm{CI}=-1.72,-0.89) \mathrm{kg} / \mathrm{cow}$ per day estimated at $-4.30 \%(95 \%$ CI $=-5.61 \%,-2.99 \%)$ of overall yield. This figure represents the average milk yield deviation per day in test-positive dairy cows in the lactation in which the animal tests positive as compared with test-negative herdmates. However, substantial study heterogeneity was observed in this analysis $\left(I^{2}=73.0\right.$ and $72.6 \%$, respectively).

Subgroup analysis by case definition (Figure 1) revealed that estimates from fecal detection case definitions resulted in greater reductions in milk production $(-1.87 \mathrm{~kg})$ than those produced from ELISA case definitions $(-1.03 \mathrm{~kg})$, although both case definitions resulted in a statistically significant decrease in daily milk production. This translated to an estimated deviation 
in milk yield of -5.90 and $-3.46 \%$ for fecal culture and ELISA, respectively (Supplementary Figure S3; http:/ / dx.doi.org/10.3168/jds.2015-10156). Furthermore, the majority of the between-study heterogeneity was observed in the ELISA subgroup $\left(I^{2}=71.2 \%\right)$. The level of between-study heterogeneity observed in the fecal subgroup was classified as unimportant $\left(I^{2}=28.9 \%\right)$.

Subgroup analysis by study design (Supplementary Figures S4 and S5; http://dx.doi.org/10.3168/jds.201510156) suggested that a small proportion of the heterogeneity could be explained by type of study. The point effect estimate for longitudinal studies was more negative than that for cross-sectional studies However, in both cases the degree of between-study heterogeneity within the subgroups was still too high to support a pooled effect estimate.

Analysis by lactation number (Figure 2 and Supplementary Figure S10; http://dx.doi.org/10.3168/ jds.2015-10156) showed a trend toward larger negative estimates with increasing lactation number; however, considerable heterogeneity within subgroups $\left(I^{2}=\right.$ 80.6-90.3\%) did not justify an overall pooled estimate by lactation number. Due to the smaller number of studies that reported by lactation $(\mathrm{n}=5)$, it was not possible to further subgroup studies according to case definition or study type.

Meta-analysis was then conducted for each case definition with study design as subgroups. Analysis by fecal culture (Supplementary Figures S6 and S7; http:// dx.doi.org/10.3168/jds.2015-10156) revealed that no heterogeneity was observed in cross-sectional studies, whereas moderate heterogeneity was observed in longitudinal studies. Point estimates were similar between subgroups, with wider confidence intervals observed in pooling of longitudinal studies. Subgroup analysis of serological-positive animals by study type revealed substantial heterogeneity was still present within subgroups (Supplementary Figures S8 and S9; http:// dx.doi.org/10.3168/jds.2015-10156).

Analysis of the effect of disease on milk fat yield (Figure 3), revealed considerable between-study heterogeneity $\left(I^{2}=76.7 \%\right)$, and a pooled estimate could only be justified for the ELISA subgroup, where infection was associated with a decline in milk fat yield of 22.1 $\mathrm{g} / \mathrm{d}$, equivalent to a $1.97 \%$ decline in overall fat yield (Supplementary Figure S11; http://dx.doi.org/10.3168/ jds.2015-10156). Analysis of the effect of paratuberculosis on protein yield (Figure 4 and Supplementary Figure S12; http://dx.doi.org/10.3168/jds.2015-10156) demonstrated considerable between-study heterogeneity $\left(I^{2}=75.1 \%\right)$ and a pooled estimate could not be justified.

The funnel plot for all study designs and case definition were relatively symmetrical, suggesting little 
Table 3. Final constructed table on effect estimates for association between paratuberculosis and daily milk yield

\begin{tabular}{|c|c|c|c|c|c|c|c|c|}
\hline Study & Country & $\begin{array}{l}\text { Case } \\
\text { definition }^{1}\end{array}$ & $\begin{array}{l}\text { Study } \\
\text { type }^{2}\end{array}$ & $\begin{array}{c}\text { Baseline } \\
\text { yield } \\
(\mathrm{kg} / \mathrm{d})\end{array}$ & $\begin{array}{c}\text { Daily } \\
\text { deviation } \\
(\mathrm{kg} / \mathrm{d})\end{array}$ & $\begin{array}{c}95 \% \text { CI } \\
(\mathrm{kg} / \mathrm{d})\end{array}$ & $\begin{array}{c}\text { Percentage } \\
\text { deviation }\end{array}$ & $95 \%$ CI (\%) \\
\hline Donat et al., 2014 & Germany & $\mathrm{FC}$ & $\mathrm{CS}$ & 29.0 & -1.30 & $-2.07,-0.53$ & -4.48 & $-7.14,-1.83$ \\
\hline Sorge et al., 2011 & Canada & ELISA $^{4}$ & $\mathrm{CS}$ & $27.7^{5}$ & -1.16 & $-2.07,-0.26$ & -4.19 & $-7.55,-0.84$ \\
\hline Aly et al., 2010 & USA & ELISA & $\mathrm{L}$ & $35.9^{6}$ & -1.58 & $-1.98,-1.19$ & -4.42 & $-5.51,-3.32$ \\
\hline Aly et al., 2010 & USA & $\mathrm{FC}$ & $\mathrm{L}$ & $35.9^{6}$ & -2.09 & $-2.42,-1.76$ & -5.82 & $-6.75,-4.89$ \\
\hline Beaudeau et al., 2007 & France & ELISA $^{4}$ & $\mathrm{CS}$ & $24.2^{9}$ & -2.39 & $-3.23,-1.54$ & -9.88 & $-13.35,-6.36$ \\
\hline Beaudeau et al., 2007 & France & $\mathrm{FC}^{4}$ & $\mathrm{CS}$ & $26.6^{9}$ & -2.30 & $-3.30,-1.29$ & -8.65 & $-12.41,-4.85$ \\
\hline Tiwari et al., 2007 & Canada & ELISA $^{4}$ & $\mathrm{CS}$ & $30.2^{3}$ & 0.16 & $-0.49,0.81$ & 0.53 & $-1.62,2.68$ \\
\hline Hendrick et al., 2005 & Canada & $\mathrm{FC}$ & $\mathrm{CS}$ & $29.2^{3}$ & -1.80 & $-3.04,-0.56$ & -6.16 & $-10.41,-1.92$ \\
\hline Hendrick et al., 2005 & Canada & ELISA & $\mathrm{CS}$ & $29.2^{3}$ & -1.50 & $-2.71,-0.28$ & -5.14 & $-9.28,-0.96$ \\
\hline Hendrick et al., 2005 & Canada & ELISA & $\mathrm{CS}$ & $29.2^{3}$ & -0.57 & $-1.56,0.42$ & -1.95 & $-5.34,1.44$ \\
\hline Spangler et al., 1988 & USA & $\mathrm{FC}$ & $\mathrm{L}$ & 25.9 & -4.87 & $-8.54,-1.20$ & -18.80 & $-32.97,-4.63$ \\
\hline
\end{tabular}

${ }^{1} \mathrm{FC}=$ fecal culture.

${ }^{2} \mathrm{~L}=$ longitudinal, $\mathrm{CS}=$ cross sectional.

${ }^{3}$ Overall average of study population (from descriptive statistics).

${ }^{4}$ Weighted average of reported effect by lactation.

${ }^{5}$ Calculated from reported percentage deviation.

${ }^{6}$ Model intercept.

${ }^{7}$ Weighted average of reported effect by test result magnitude.

${ }^{8}$ Average milk production in geographical region for duration of sampling period.

${ }^{9}$ Reported average yield for noninfected adult (lactation $\geq 3$ ) cow.

publication bias (Figure 5), and Egger's test revealed no significant bias $(P=0.334)$. In addition, the funnel plot also revealed 2 distinct clusters of SE between 0.25 to 0.75 and 1.5 to 2.0. Further analysis revealed that study SE was significantly associated with year of publication and study design. Longitudinal studies and those published earlier produced estimates with a larger SE, whereas cross-sectional and more recent studies produced smaller SE.
Finally, a sensitivity analysis was undertaken. Decisions made around the selection criteria were tested by dropping particular studies and repeating the analysis. When studies reporting an improvement in milk yield were removed, small changes in the overall point estimates were observed, -1.91 and $-1.26 \mathrm{~kg}$ for fecal culture and ELISA, respectively. However, between-study heterogeneity dropped substantially for the ELISA subgroup (44.6\%), indicating that the Johnson et al.

Table 4. Summary of meta-analyses investigating the effect of paratuberculosis on milk yield

\begin{tabular}{|c|c|c|c|c|c|c|c|}
\hline Model & Subgroup & $\begin{array}{l}\text { Effect } \\
\text { size } \\
(\mathrm{kg} / \mathrm{d})\end{array}$ & $95 \%$ CI & $\begin{array}{l}\text { Between-study } \\
\text { heterogeneity } \\
\qquad\left(I^{2}\right)\end{array}$ & $\begin{array}{l}\text { Effect size } \\
\text { (\% of overall } \\
\text { yield) }\end{array}$ & $95 \% \mathrm{CI}$ & $\begin{array}{l}\text { Between-study } \\
\text { heterogeneity } \\
\qquad\left(I^{2}\right)\end{array}$ \\
\hline Overall & & -1.30 & $-1.72,-0.89$ & $73.0 \%$ & -4.30 & $-5.61,-2.99$ & $72.6 \%$ \\
\hline \multirow{2}{*}{ Case Definition } & Fecal culture & -1.87 & $-2.34,-1.40$ & $28.9 \%$ & -5.90 & $-7.50,-4.29$ & $29.6 \%$ \\
\hline & ELISA & -1.03 & $-1.53,-0.54$ & $71.2 \%$ & -3.46 & $-5.09,-1.83$ & $72.2 \%$ \\
\hline \multirow[t]{2}{*}{ Study Design } & Cross sectional & -1.23 & $-1.69,-0.78$ & $66.6 \%$ & -4.36 & $-6.05,-2.68$ & $72.5 \%$ \\
\hline & Longitudinal & -1.58 & $-2.31,-0.84$ & $62.8 \%$ & -4.64 & $-6.67,-2.61$ & $60.2 \%$ \\
\hline \multirow[t]{3}{*}{ Lactation Number } & 1 & -0.34 & $-1.08,0.40$ & $81.3 \%$ & -1.38 & $-4.18,1.42$ & $82.5 \%$ \\
\hline & 2 & -1.11 & $-2.08,-0.15$ & $80.6 \%$ & -3.72 & $-6.89,-0.54$ & $81.6 \%$ \\
\hline & $3+$ & -1.50 & $-2.71,-0.29$ & $90.3 \%$ & -4.76 & $-8.78,-0.75$ & $91.6 \%$ \\
\hline \multirow[t]{2}{*}{ Fecal Culture } & Cross sectional & -1.74 & $-2.26,-1.22$ & $0.0 \%$ & -6.17 & $-8.18,-4.17$ & $11.9 \%$ \\
\hline & Longitudinal & -1.68 & $-3.38,0.03$ & $51.9 \%$ & -4.97 & $-10.69,0.75$ & $53.5 \%$ \\
\hline \multirow{2}{*}{ ELISA } & Cross sectional & -1.01 & $-1.53,-0.48$ & $68.7 \%$ & -3.51 & $-5.43,-1.59$ & $73.3 \%$ \\
\hline & Longitudinal & -0.50 & $-2.97,1.96$ & $65.0 \%$ & -1.69 & $-9.08,5.70$ & $57.7 \%$ \\
\hline
\end{tabular}




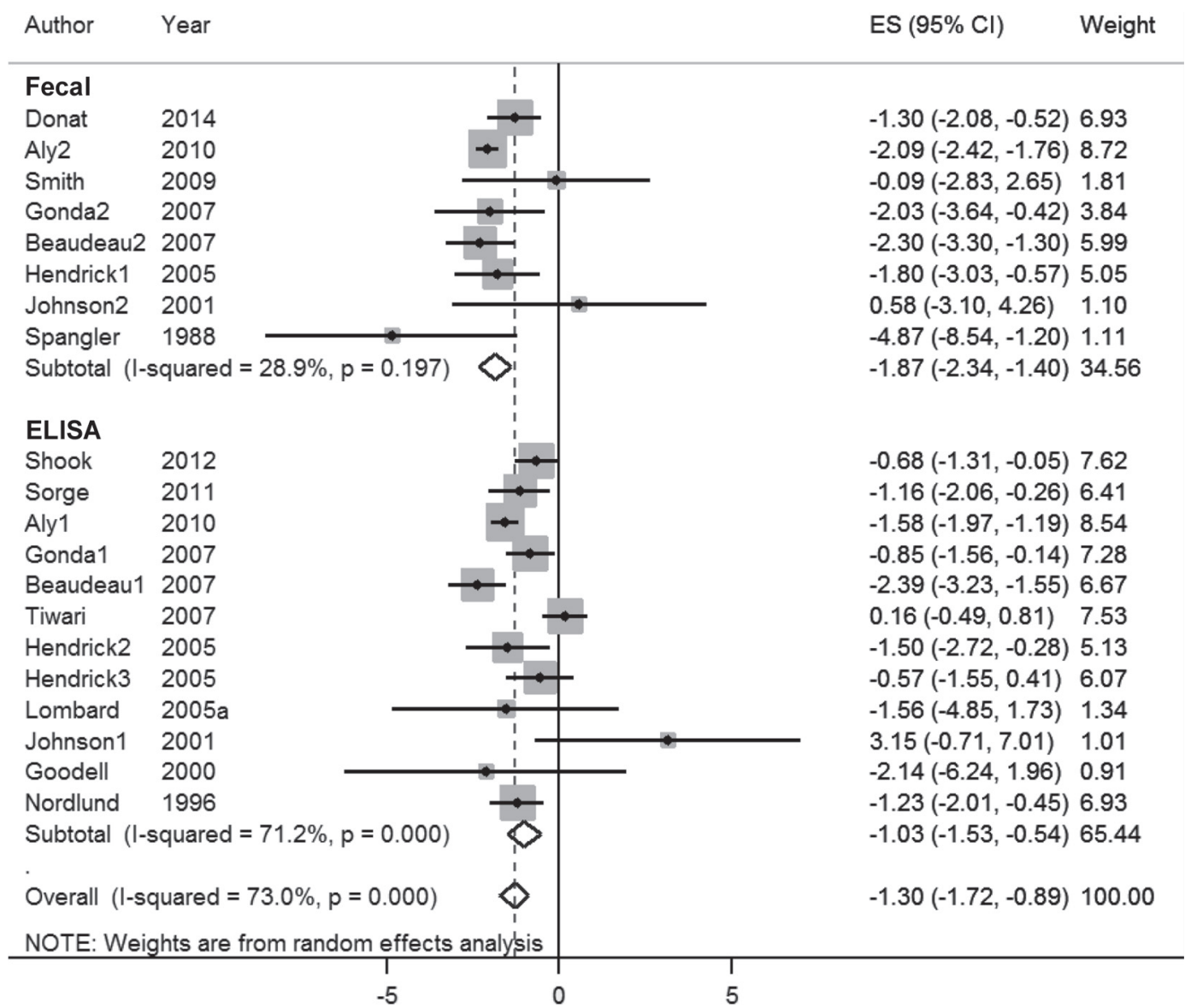

Figure 1. A forest plot of the effect size (ES) and 95\% confidence intervals (CI) for studies investigating the association between paratuberculosis diagnostic test positivity and deviation in milk production in individual cows compared with test-negative herdmates. The studies have been subgrouped according to case definition. Point estimates and CI for each study are presented on each line. Relative weighting of each study is represented by the gray box surrounding the point estimate. Combined effect estimates $(\diamond)$ are presented at the bottom of each subgroup. Studies are listed by first author's last name and year only.

(2001) study was responsible for a significant proportion of the heterogeneity observed in the original analysis. When data based on an assumed $P$-value $(0.05)$ were excluded, only the ELISA subgroup was affected. The effect on the point estimate was minimal $(-1.02$ $\mathrm{kg}$ ) and an increase in between-study variation was observed $\left(I^{2}=73.8 \%\right)$

\section{DISCUSSION}

The aim of our study was to investigate the effect of paratuberculosis on milk yield. Using either ELISA positivity or fecal detection as the case definition resulted in a statistically significant reduction in milk yield associated with paratuberculosis, albeit with varying levels of between-study heterogeneity.

Pooling of study data could be justified for studies using fecal detection methods given the acceptable level of between-study variation. In this instance the calculated combined effect was $-1.87 \mathrm{~kg} /$ cow per day or $-576.45 \mathrm{~kg} / \mathrm{cow}$ per $305 \mathrm{~d}$ of lactation, estimated at $-5.90 \%$ of milk yield. This figure represents the deviation in milk yield in the lactation corresponding to when the animal tests positive for paratuberculosis and is corrected for the lactation number or age of the cow and the herd of origin of the animal.

Interestingly, point estimates from studies utilizing fecal culture as the case definition tended to find a deviation in milk yield that was greater than that found by studies utilizing ELISA as the diagnostic test. One possible explanation for this is that the specificity of fecal culture is assumed to be close to $100 \%$, whereas ELISA specificity is generally reported to be somewhat less than fecal culture (Nielsen and Toft, 2008). Positive predictive values of test-positive animals vary strongly according to prevalence (Brenner and Gefeller, 1997); therefore, in low animal-level seroprevalence conditions, such as paratuberculosis, a greater proportion of false positive serological results may be expected. It is likely that the ELISA case definition may have falsely 


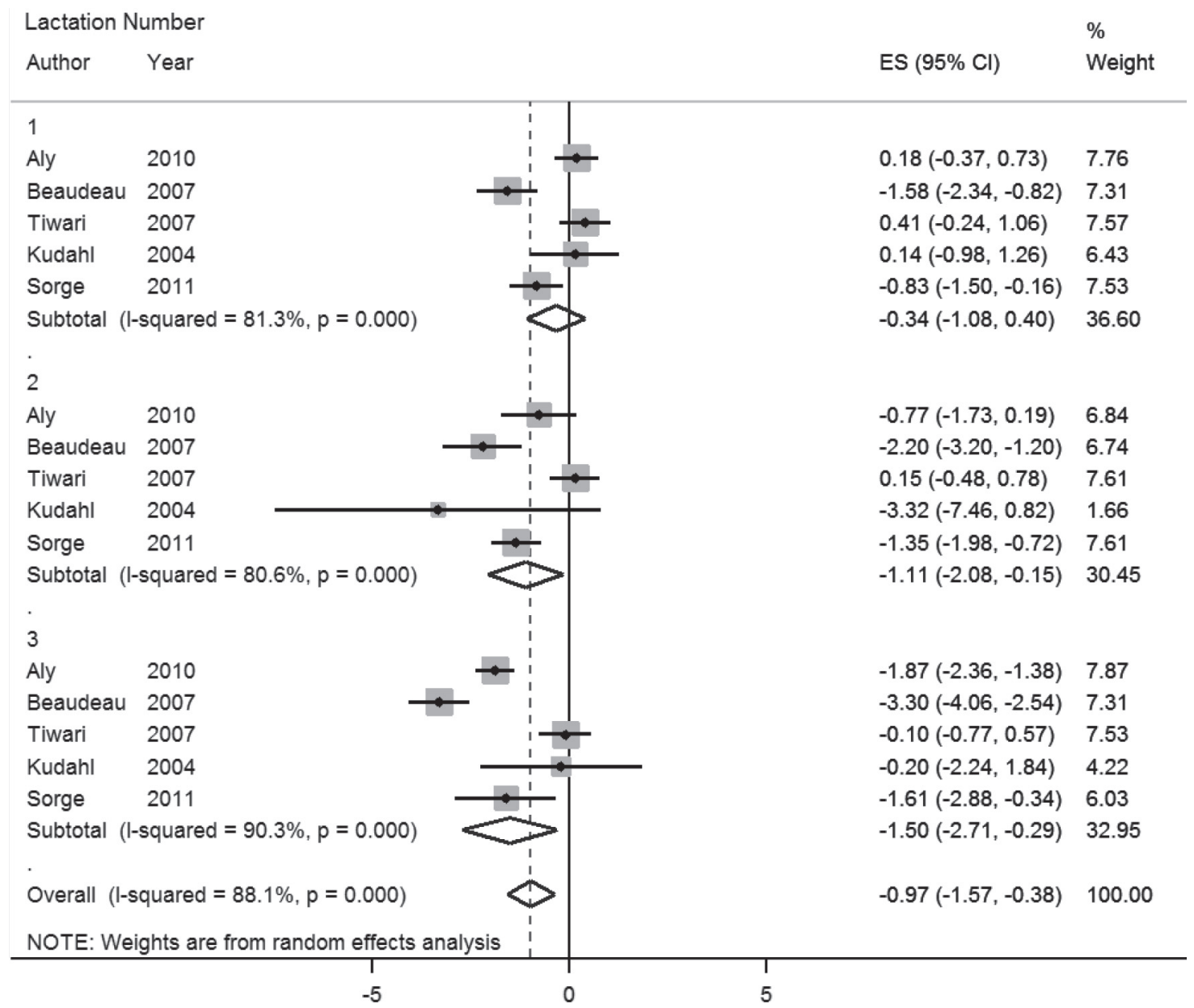

Figure 2. A forest plot of the effect size (ES) and 95\% confidence intervals (CI) for studies investigating the association between paratuberculosis diagnostic test positivity and deviation in milk production in individual cows compared with test-negative herdmates. The studies have been subgrouped according to lactation number. Point estimates and CI for each study are presented on each line. Relative weighting of each study is represented by the gray box surrounding the point estimate. Combined effect estimates $(\diamond)$ are presented at the bottom of each subgroup. Studies are listed by first author's last name and year only.

identified a proportion of animals as infected, possibly resulting in under-estimation of the effect of infection. Estimates of the pooled serology studies are included for discussion; however, the substantial between-study heterogeneity would suggest that pooling of these estimates was not justified. The characteristics of diagnostic tests are assumed to vary within and among animal populations (Greiner and Gardner, 2000). This variation may be greater in serological testing than in fecal culture, possibly resulting in greater variation between populations and, therefore, between studies.

It is possible that a culling bias may have affected the validity of the effect estimates reported in the studies analyzed here. In this case, a culling bias would manifest as an underestimation of the detrimental effect of paratuberculosis on milk production. Low-producing animals within the test-positive population would likely be disproportionally culled from the herd, resulting in an inflated estimate of milk yield in the test-positive population.

Several other factors are likely to affect any effect estimate. Smith et al. (2009) found that latently infected animals and low-fecal shedding cows produced more milk than uninfected herdmates, with a decline in milk production only observed in high-shedding animals. Similarly, Nielsen et al. (2009) investigated the time to the occurrence of a milk drop in animals with different antibody profiles and discovered that cows that became test positive may produce more milk than negative herdmates 200 to $400 \mathrm{~d}$ before testing positive. Therefore, stage of infection is likely an important effect modifier at the individual animal level. Stagespecific definitions of infected, infectious, and affected are often used with regard to paratuberculosis (Nielsen 


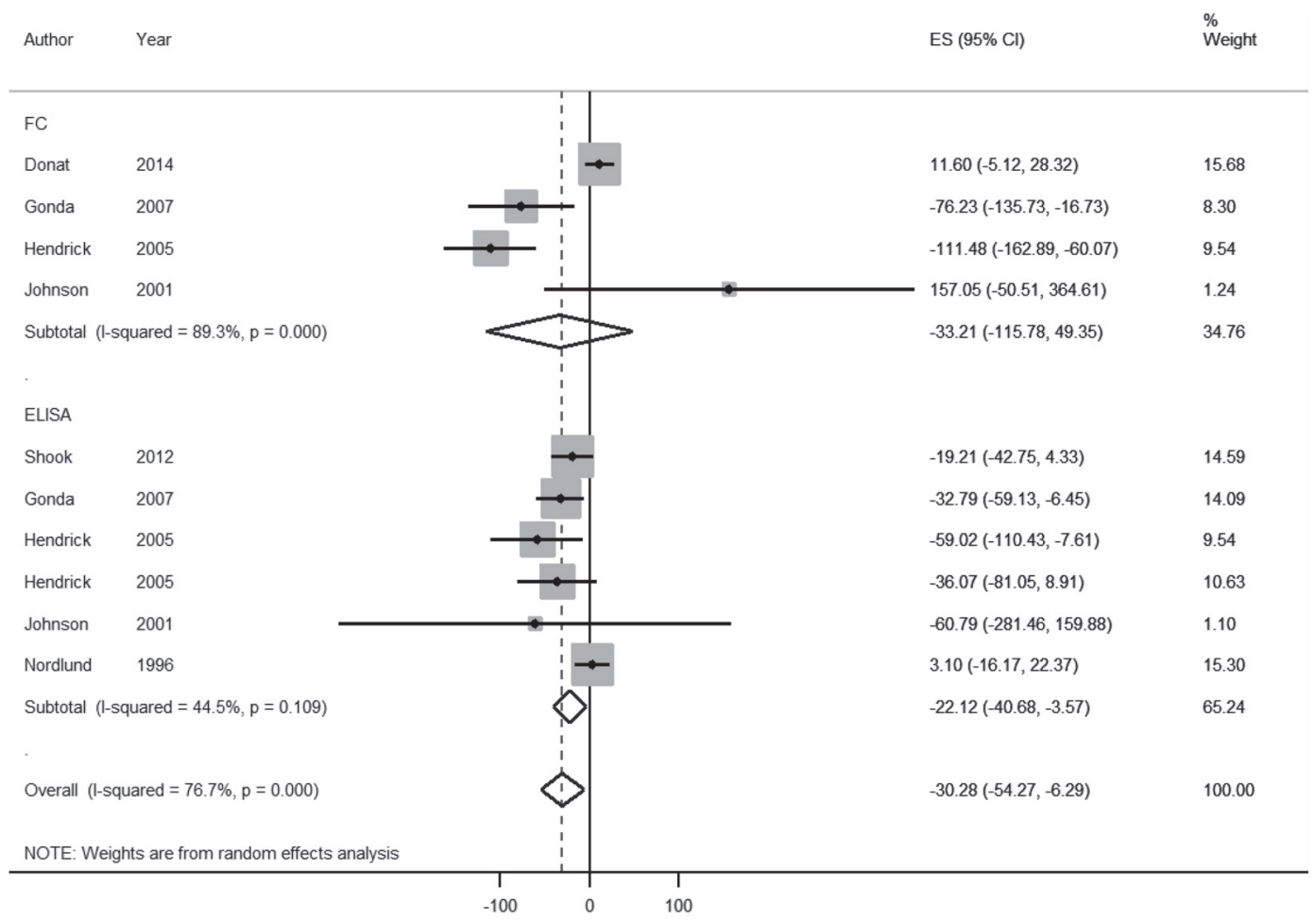

Figure 3. A forest plot of the effect size (ES) and 95\% confidence intervals (CI) for studies investigating the association between paratuberculosis diagnostic test positivity and deviation in milk fat yield ( $\mathrm{g} / \mathrm{cow}$ per day) in individual cows compared with test-negative herdmates. The studies have been subgrouped according case definition. Point estimates and CI for each study are presented on each line. Relative weighting of each study is represented by the gray box surrounding the point estimate. Combined effect estimates $(\diamond)$ are presented at the bottom of each subgroup. Studies are listed by first author's last name and year only.

and Toft, 2008). However, analysis at this level was not possible given the case definitions used in the studies available. The case definition instead was diagnostic test positivity either by serological or organism-detection methods. This case definition excludes the infected or latent subgroup, and is primarily an estimation of infections, although it is likely that a small number of affected animals would also be included in the analysis.

The majority of models in this analysis concluded that paratuberculosis was associated with a statistically significant decline in milk production. However, the magnitude of the deviation represents a relatively modest decline in milk yield at the individual animal level. Herd-level production losses, and therefore the financial cost of the disease to the farmer, will ultimately depend on the within-herd prevalence. As discussed, these reductions are likely to be most representative of the subclinically infected infectious population of cows in the herd, and it is expected that production losses for animals displaying clinical signs will be much greater. Therefore, the financial cost to the farmer will also depend heavily on the relative proportions of latent, infectious, and affected animals within the herd. Interestingly, Donat et al. (2014) investigated the effect of within-herd prevalence on the magnitude of the deviation in individual animal milk yield and found a greater decline associated with test positivity in herds where a greater within-herd prevalence was recorded. This observation is relatively recent and has not been reported in a sufficient number of studies to allow formal comparison. However, a possible explanation for this finding is that the relative proportion of infectious and affected animals, as diagnosed through fecal culture or ELISA, is likely to vary according to within-herd prevalence. Diagnostic test sensitivity is known to increase with disease progression; therefore, the population of diagnostic test-positive animals in a herd with a high prevalence is likely to contain a greater proportion of animals in the advanced stages of the disease as compared with a herd with a low withinherd prevalence. This may be reflected as a greater reduction in milk yield in the test-positive population.

Analysis of milk constituents was hindered by the relatively low number of studies that reported on this outcome. However, a pooled estimate could be calculated for the association between diagnostic test positivity on milk fat production. In this case, the decline in milk fat yield was around $22.1 \mathrm{~g} /$ cow per day or $6.75 \mathrm{~kg} / \mathrm{cow}$ 


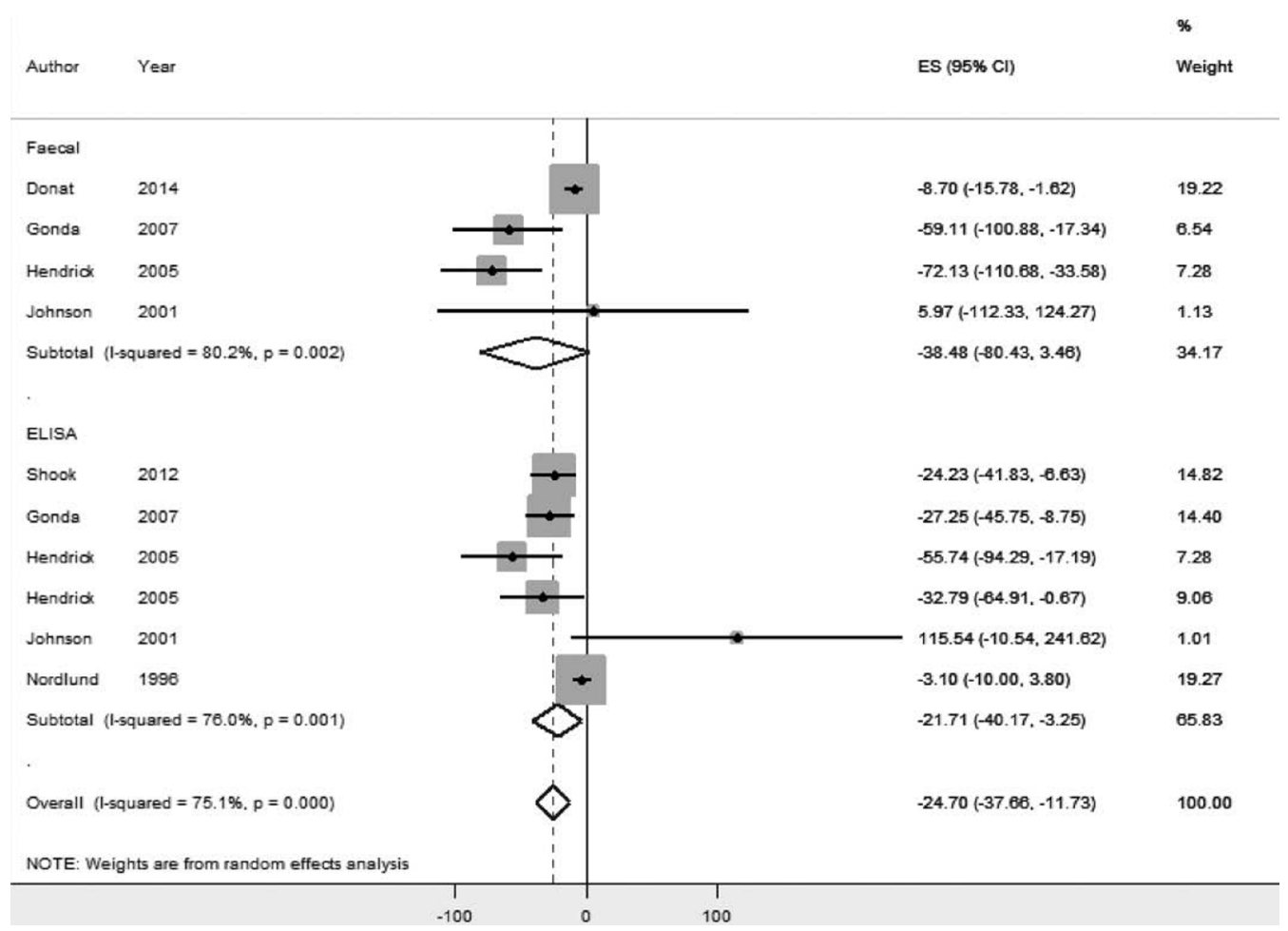

Figure 4. A forest plot of the effect size (ES) and 95\% confidence intervals (CI) for studies investigating the association between paratuberculosis diagnostic test positivity and deviation in milk protein yield (g/cow per day) in individual cows compared with test-negative herdmates. The studies have been subgrouped according case definition. Point estimates and CI for each study are presented on each line. Relative weighting of each study is represented by the gray box surrounding the point estimate. Combined effect estimates $(\diamond)$ are presented at the bottom of each subgroup. Studies are listed by first author's last name and year only.

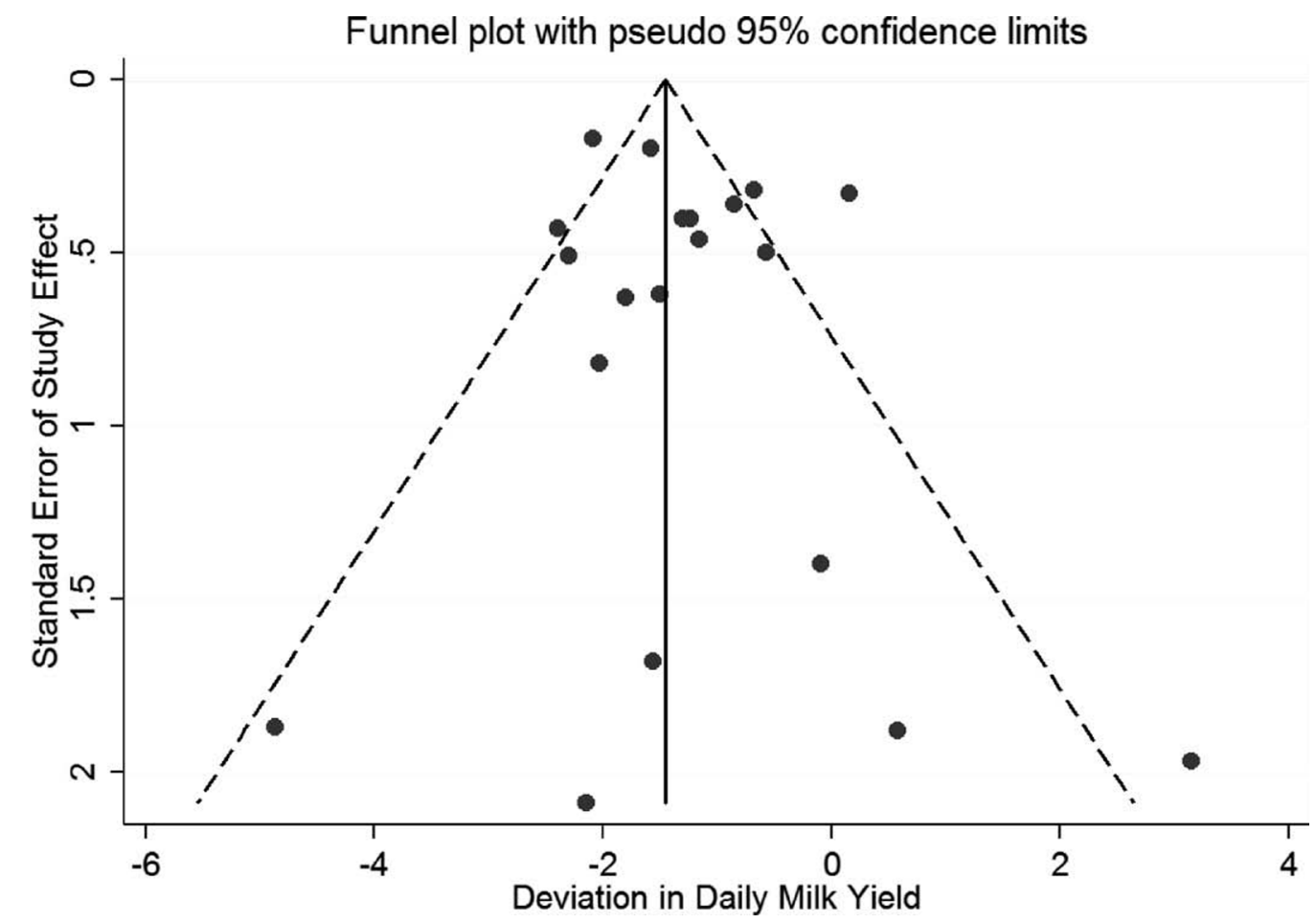

Figure 5. A funnel plot of deviation in milk yield associated with paratuberculosis in dairy cattle. Each study is represented (•). Plot displays relative symmetry and Egger's test revealed no significant bias $(P=0.334)$. 
per $305 \mathrm{~d}$ of lactation, equivalent to a $2 \%$ reduction in milk fat production. Again, this finding suggests a modest effect of paratuberculosis on milk production at the individual animal level. A pooled estimate could not be calculated for protein yield given the large between-study heterogeneity observed in these studies.

\section{CONCLUSIONS}

This systematic review and meta-analysis demonstrated that, although paratuberculosis was associated with a statistically significant decline in milk production, the magnitude of the decline was relatively modest. A pooled effect estimate was only indicated for studies that used fecal organism detection as the case definition. In this instance, a decline in milk production associated with diagnostic test positivity of $1.87 \mathrm{~kg} /$ cow per day $(95 \% \mathrm{CI}=2.34,1.40)$ was found; this was calculated to be equivalent to $5.9 \%$ of overall production.

\section{ACKNOWLEDGMENTS}

This study was carried out as part of the ICONMAP multidisciplinary research program, funded by the Irish Department of Agriculture, Food and the Marine.

\section{REFERENCES}

Abbas, B., H. Riemann, and D. Hird. 1983. Diagnosis of Johne's disease (paratuberculosis) in northern California cattle and a note on its economic significance. Calif. Vet. 8:20-24.

Aly, S. S., R. Anderson, J. Adaska, J. Jiang, and I. Gardner. 2010. Association between Mycobacterium avium subspecies paratuberculosis infection and milk production in two California dairies. J. Dairy Sci. 93:1030-1040.

Ansari-Lari, M., M. Haghkhah, and F. Mahmoodi. 2012. Association of Mycobacterium avium subspecies paratuberculosis infection with milk production and calving interval in Iranian Holsteins. Trop. Anim. Health Prod. 44:1111-1116.

Beaudeau, F., M. Belliard, A. Joly, and H. Seegers. 2007. Reduction in milk yield associated with Mycobacterium avium subspecies paratuberculosis (Map) infection in dairy cows. Vet. Res. 38:625-634.

Benedictus, G., A. A. Dijkhuizen, and J. Stelwagen. 1986. The economic losses due to paratuberculosis in cattle. Pages 288-291 in Fourteenth World Congress on Diseases of Cattle Dublin, Ireland. Irish Cattle Veterinary Association, Ireland.

Benedictus, G., A. A. Dijkhuizen, and J. Stelwagen. 1987. Economic losses due to paratuberculosis in dairy cattle. Vet. Rec. 121:142146 .

Blettner, M., W. Sauerbrei, B. Schlehofer, T. Scheuchenpflug, and C. Friedenreich. 1999. Traditional reviews, meta-analyses and pooled analyses in epidemiology. Int. J. Epidemiol. 28:1-9.

Brenner, H., and O. Gefeller. 1997. Variation of sensitivity, specificity, likelihood ratios and predictive values with disease prevalence. Stat. Med. 16:981-991.

Buergelt, C. D., and J. Duncan. 1978. Age and milk production data of cattle culled from a dairy herd with paratuberculosis. J. Am. Vet. Med. Assoc. 173:478-480.

Chaffer, M., K. Grinberg, E. Ezra, and D. Elad. 2002. The effect of sub-clinical Johne's disease on milk production, fertility and milk quality in Israel. Pages 351-352 in Proc. 7th Int. Colloq. Paratuberculosis, Bilbao, Spain. International Association for Paratuberculosis, Bilbao, Spain.

Chi, J., J. A. VanLeeuwen, A. Weersink, and G. P. Keefe. 2002. Direct production losses and treatment costs from bovine viral diarrhoea virus, bovine leukosis virus, Mycobacterium avium subspecies paratuberculosis, and Neospora caninum. Prev. Vet. Med. 55:137-153.

Chiodini, R. J., W. M. Chamberlin, J. Sarosiek, and R. W. McCallum. 2012. Crohn's disease and the mycobacterioses: A quarter century later. Causation or simple association? Crit. Rev. Microbiol. 38:52-93.

Collins, M. T. N. K. 1991. Milk Production levels in cows ELISA positive for serum antibodies to M. paratuberculosis Page 23 in Proc. 3rd Int. Colloq. Paratuberculosis. Orlando, FL. International Association for Paratuberculosis, Orlando, FL.

Deeks, J. J., Higgins, J. and Altman, D. G. 2008. Analysing data and undertaking meta-analyses. Pages 243-296 in Cochrane Handbook for Systematic Reviews of Interventions: Cochrane Book Series. John Wiley \& Sons Ltd, Chichester, UK.

DeLisle, G. W. d., and B. A. Milestone. 1989. The economic impact of Johne's disease in New Zealand. Pages 41-45 in Johne's Disease: Current Trends in Research, Diagnosis and Management. A. R. Milner and P. R. Wood, ed. CSIRO, Melbourne, Australia.

Dinsmore, R. P. 1986. Effects of paratuberculosis in a research dairy herd. Page 20 in Proc. 3rd Northeast Region Meeting on Paratuberculosis, Ithaca, NY. International Association for Paratuberculosis, Ithaca, NY.

Donat, K., A. Soschinka, G. Erhardt, and H. R. Brandt. 2014. Paratuberculosis: Decrease in milk production of German Holstein dairy cows shedding Mycobacterium avium ssp. paratuberculosis depends on within-herd prevalence. Animal 8:852-858.

EFSA. 2010. Application of systematic review methodology to food and feed safety assessments to support decision making. EFSA J. $8: 1637$

Egger, M., G. D. Smith, M. Schneider, and C. Minder. 1997. Bias in meta-analysis detected by a simple, graphical test. BMJ 315:629 634

Garcia, A. B., and L. Shalloo. 2015. Invited review: The economic impact and control of paratuberculosis in cattle. J. Dairy Sci. 98:5019-5039.

Geraghty, T., D. A. Graham, P. Mullowney, and S. J. More. 2014. A review of bovine Johne's disease control activities in 6 endemically infected countries. Prev. Vet. Med. 116:1-11.

Gonda, M. G., Y. Chang, G. Shook, M. Collins, and B. Kirkpatrick. 2007. Effect of Mycobacterium paratuberculosis infection on production, reproduction, and health traits in US Holsteins. Prev. Vet. Med. 80:103-119.

Goodell, G., H. Hirst, F. Garry, and P. Dinsmore. 2000. Comparison of cull rates and milk production of clinically normal dairy cows grouped by ELISA Mycobacterium avium paratuberculosis serum antibody results. Abstract ID 579 in Proc. Int. Symposium Vet. Epidemiol. Econ., Breckenridge, CO. International Society for Veterinary Epidemiology and Economics, Colorado State Univ., Ft. Collins.

Greiner, M., and I. A. Gardner. 2000. Epidemiologic issues in the validation of veterinary diagnostic tests. Prev. Vet. Med. 45:3-22.

Harris, R., M. Bradburn, J. Deeks, R. Harbord, D. Altman, and J. Sterne. 2008. Metan: Fixed-and random-effects meta-analysis. Stata J. 8:3-28.

Hendrick, S. H., T. F. Duffield, D. F. Kelton, K. E. Leslie, K. D. Lissemore, and M. Archambault. 2005. Evaluation of enzyme-linked immunosorbent assays performed on milk and serum samples for detection of paratuberculosis in lactating dairy cows. J. Am. Vet. Med. Assoc. 226:424-428.

Higgins, J., and S. Green. 2011. Cochrane Handbook for Systematic Reviews of Interventions Version 5.1. The Cochrane Collaboration. Accessed Jun. 1, 2015. http://www.cochrane-handbook.org.

Higgins, J. P., and S. G. Thompson. 2002. Quantifying heterogeneity in a meta-analysis. Stat. Med. 21:1539-1558.

Higgins, J. P., S. G. Thompson, J. J. Deeks, and D. G. Altman. 2003. Measuring inconsistency in meta-analyses. BMJ 327:557. 
Hoogendam, K., E. Richardson, and J. F. Mee. 2009. Paratuberculosis sero-status and milk production, SCC and calving interval in Irish dairy herds. Ir. Vet. J. 62:265-271.

Johnson, Y. J., J. Kaneene, J. Gardiner, J. Lloyd, D. Sprecher, and P. Coe. 2001. The effect of subclinical Mycobacterium paratuberculosis infection on milk production in Michigan dairy cows. J. Dairy Sci. 84:2188-2194.

Kudahl, A., S. S. Nielsen, and J. T. Sørensen. 2003. Effects of paratuberculosis on productivity in Danish dairy cows. Acta Vet. Scand. 44:P96.

Kudahl, A., S. S. Nielsen, and J. T. Sørensen. 2004. Relationship between antibodies against Mycobacterium avium ssp. paratuberculosis in milk and shape of lactation curves. Prev. Vet. Med. 62:119-134.

Lombard, J. E., F. B. Garry, B. J. McCluskey, and B. A. Wagner. 2005a. Risk of removal and effects on milk production associated with paratuberculosis status in dairy cows. J. Am. Vet. Med. Assoc. 227:1975-1981.

Lombard, J. E., B. A. Wagner, B. J. McCluskey, and F. B. Garry. 2005b. Production effects of Mycobacterium avium subspecies paratuberculosis infection based on diagnostic test results. Page 189 in Proc. 38th Am. Assoc. Bovine Pract. Conf., Salt Lake City, UT. American Association of Bovine Practitioners. Stillwater, OK.

Nielsen, S. S., M. A. Krogh, and C. Enevoldsen. 2009. Time to the occurrence of a decline in milk production in cows with various paratuberculosis antibody profiles. J. Dairy Sci. 92:149-155.

Nielsen, S. S., and N. Toft. 2008. Ante mortem diagnosis of paratuberculosis: A review of accuracies of ELISA, interferon- $\gamma$ assay and faecal culture techniques. Vet. Microbiol. 129:217-235.

Nordlund, K. V., W. Goodger, J. Pelletier, and M. Collins. 1996. Associations between subclinical paratuberculosis and milk production, milk components, and somatic cell counts in dairy herds. J. Am. Vet. Med. Assoc. 208:1872-1876.

Ott, S. L., S. J. Wells, and B. A. Wagner. 1999. Herd-level economic losses associated with Johne's disease on US dairy operations. Prev. Vet. Med. 40:179-192.

Pantoja, J., B. Vallejo, and J. Acosta. 2010. Bovine paratuberculosis in Puerto Rican dairy herds and its association with selected performance parameters. J. Agric. Univ. P R. 94:247-254.

Pavlík, I., M. Pavlas, and L. Bejčková. 1994. Incidence, economic importance and diagnosis of paratuberculosis. Veterinarni Medicina 39:451-496.

Rad, A. H. F., M. R. Bassami, and A. Mirzapoor. 2010. Prevalence of MAP in a large dairy herd and its effect on reproductive and production indices. J. Anim. Vet. Adv. 9:149-154.

Raizman, E. A., J. Fetrow, S. J. Wells, S. M. Godden, M. J. Oakes, and G. Vazquez. 2007. The association between Mycobacterium avium ssp. paratuberculosis fecal shedding or clinical Johne's disease and lactation performance on two Minnesota, USA dairy farms. Prev. Vet. Med. 78:179-195.

Raizman, E. A., J. P. Fetrow, and S. J. Wells. 2009. Loss of income from cows shedding Mycobacterium avium subspecies paratuberculosis prior to calving compared with cows not shedding the organism on two Minnesota dairy farms. J. Dairy Sci. 92:4929-4936.

Richardson, E., and S. J. More. 2009. Direct and indirect effects of Johne's disease on farm and animal productivity in an Irish dairy herd. Ir. Vet. J. 62:526

Shook, G. E., M. Chaffer, X. L. Wu, and E. Ezra. 2012. Genetic parameters for paratuberculosis infection and effect of infection on production traits in Israeli Holsteins. Anim. Genet. 43:56-64.

Sibley, R. J., P. G. Orpin, and H. L. Pearse. 2012. Fertility, udder health and milk production in cows that have high milk antibod- ies to paratuberculosis. Pages 194-195 in Proc. 11th Int. Colloq. Paratuberculosis, Sydney, Australia. International Association for Paratuberculosis, Sydney, Australia.

Smith, R. L., Y. Grohn, A. Pradhan, R. Whitlock, J. Van Kessel, J. Smith, D. Wolfgang, and Y. Schukken. 2009. A longitudinal study on the impact of Johne's disease status on milk production in individual cows. J. Dairy Sci. 92:2653-2661.

Sorge, U., D. Kelton, J. Jansen, A. Godkin, and R. Cantin. 2007. Association between paratuberculosis milk ELISA test result and milk production and breed in dairy cows. Page 228 in Proc. 40th Am. Assoc. Bovine Pract. Conf. Vancouver, British Colombia, Canada.

Sorge, U. S., K. Lissemore, A. Godkin, S. Hendrick, S. Wells, and D. Kelton. 2011. Associations between paratuberculosis milk ELISA result, milk production, and breed in Canadian dairy cows. J. Dairy Sci. 94:754-761.

Spangler, E., S. Bech Nielsen, and L. E. Heider. 1988. A study of subclinical paratuberculosis in three central Ohio dairy herds. Acta Vet. Scand. Suppl. 84:148-150.

Stott, A. W., G. M. Jones, R. W. Humphry, and G. J. Gunn. 2005 Financial incentive to control paratuberculosis (Johne's disease) on dairy farms in the United Kingdom. Vet. Rec. 156:825-831.

Stroup, D. F., J. A. Berlin, S. C. Morton, I. Olkin, G. D. Williamson, D. Rennie, D. Moher, B. J. Becker, T. A. Sipe, and S. B. Thacker 2000. Meta-analysis of observational studies in epidemiology: A proposal for reporting. JAMA 283:2008-2012.

Sweeney, R., L. Hutchinson, R. Whitlock, D. Galligan, and P. Spencer 1994. Effect of Mycobacterium paratuberculosis infection on milk production in dairy cattle. Pages 133-139 in Proc. 4th Int. Colloq. Paratuberculosis, Cambridge, UK. International Association for Paratuberculosis, Cambridge, UK.

Sweeney, R. W., M. T. Collins, A. P. Koets, S. M. McGuirk, and A. J. Roussel. 2012. Paratuberculosis (Johne's disease) in cattle and other susceptible species. J. Vet. Intern. Med. 26:1239-1250.

Tiwari, A., J. A. VanLeeuwen, I. R. Dohoo, G. P. Keefe, J. Haddad, R. Tremblay, H. Scott, and T. Whiting. 2007. Production effects of pathogens causing bovine leukosis, bovine viral diarrhea, paratuberculosis, and neosporosis. J. Dairy Sci. 90:659-669.

USDA. 2015. National Statistics for Milk. USDA-National Agricultura Statistics Service. Accessed Oct. 1, 2015. http://www.nass. usda.gov/Statistics_by_Subject/result.php?4B229587-F30834B9-8E3F-A02380B426BD\&sector $=$ ANIMALS $\% 20 \% 26 \% 20$ PRODUCTS\&group $=$ DAIRY\&comm $=$ MILK.

VanLeeuwen, J. A., G. P. Keefe, and A. Tiwari. 2002. Seroprevalence and productivity effects of infection with bovine leukemia virus, Mycobacterium avium subspecies paratuberculosis, and Neospora caninum in maritime Canadian dairy cattle. Bovine Pract. 36:8691.

Villarino, M. A., H. Scott, and E. Jordan. 2011. Influence of parity at time of detection of serologic antibodies to subspecies on reduction in daily and lifetime milk production in Holstein cows. J. Anim. Sci. 89:267-276.

Whitlock, R. H., L. J. Hutchinson, R. S. Merkal, L. T. Glickman, C. Rossiter, S. Harmon, P. Spencer, J. Fetrow, J. Bruce, C. E. Benson, and J. Dick. 1985. Prevalence and economic considerations of Johne's disease in Northeastern US. Pages 484-490 in 89th Annual Meeting US Anim. Health Assoc. Milwaukee, WI

Wilson, D. J., C. Rossiter, H. R. Han, and P. M. Sears. 1993. Association of Mycobacterium paratuberculosis infection with reduced mastitis, but with decreased milk production and increased cull rate in clinically normal dairy cows. Am. J. Vet. Res. 54:1851-1857. 